\title{
NOVA TECNOLOGIA DE MASSA DE TAMPONAMENTO COMO ALTERNATIVA PARA O CONTROLE DE PONTOS QUENTES NA PAREDE DO CADINHO DE ALTOS-FORNOS*
}

\author{
Aloísio Simões Ribeiro ${ }^{1}$ \\ Humberto Chiaretti Bassalo ${ }^{2}$ \\ Pedro Mandaj Filho ${ }^{3}$ \\ Alexander Rabello Ollmann 4 \\ Gustavo Serrano dos Santos 5 \\ César Almeida Assis ${ }^{6}$ \\ Marcos de Jesus Nonato ${ }^{7}$
}

\section{Resumo}

Para a preservação e extensão da campanha do Alto-Forno é de fundamental importância o monitoramento, controle e estabilização da temperatura de pontos quentes na parede do cadinho do forno, possíveis de serem gerados durante a sua campanha operacional. Já são bem conhecidas diversas práticas operacionais para controle dos pontos quentes sendo que, uma das mais usuais, é o uso na carga do forno ou injeção via ventaneiras de fontes de óxido de titânio para formar, junto à parede do cadinho, uma camada protetora composta por carbonitreto de titânio. Neste trabalho será apresentado o desenvolvimento de uma nova concepção de massa de tamponamento contendo dióxido de titânio sintético, para auxiliar em problemas de pontos quentes em regiões do cadinho próximas aos furos de corrida. Palavras-chave: Alto-forno; Massa de tamponamento; Óxido de titânio; Refratário.

\section{NEW TECHNOLOGY OF TAPHOLE MIX FOR BLAST FURNACE TO PREVENT THE HOT SPOT ON THE HEARTH WALL}

\begin{abstract}
To maintain and extend the blast furnace campaign it is important to check, control and stabilize the temperature of the hot spots on the blast furnace hearth wall. It is well known some practices to control the hot spots including the use of titanium oxide in the burden lump ore and the injection of synthetic titanium oxide through tuyeres to prevent the wear on the hearth wall by creating a protective layer composed by titanium carbonitride. This paper presents a new taphole mix for blast furnace containing synthetic titanium oxide to prevent the hot spot incidence on the hearth wall close to the taphole.
\end{abstract}

Keywords: Blast furnace; Taphole clay; Titanium oxide; Refractory.

1 Engenheiro Metalurgista, MSc. Engenharia de Materiais, Pesquisador da Magnesita Refratários, Belo Horizonte, MG, Brasil.

2 Engenheiro Metalurgista, MSc. Engenharia Cerâmica, Consultor na Magnesita Refratários, Belo Horizonte, MG, Brasil.

3 Técnico Metalúrgico, Analista de Gestão de Contratos da Magnesita Refratários, Belo Horizonte, MG, Brasil.

4 Engenheiro Metalurgista, Especialista da área de Redução da Magnesita Refratários, Belo Horizonte, MG, Brasil.

5 Engenheiro Metalurgista, Gerente Geral da área de Redução, Santos, SP, Brasil.

6 Engenheiro Metalurgista, Gerente de Altos-Fornos, Ipatinga, MG, Brasil.

7 Técnico Metalúrgico, Assistente Industrial da área de Altos-Fornos, Ipatinga, MG, Brasil. 


\section{INTRODUÇÃO}

Nos Altos-Fornos, o cadinho é uma região que sofre grande solicitação em função de fatores relacionados ao intenso fluxo de metal líquido, ataque químico e abrasivo da escória e gusa, entre outros. Além disso é o cadinho que, de uma maneira geral, determina a extensão da campanha de um Alto-Forno. Portanto, métodos dos quais podem preservar a parede do cadinho e, por consequência, estender a campanha de um Alto-forno sem interrupção da produção são, além de grande interesse técnico, também de grande importância econômica para a produção de ferro gusa.

Já são bem conhecidos os procedimentos operacionais adotados para minimizar problemas de desgaste excessivos da parede do cadinho de Altos-Fornos a coque. Geralmente estes desgastes podem levar a problemas de aumento de temperatura da parede conhecidos como pontos quentes. Dentre estes procedimentos operacionais para controle e prevenção dos pontos quentes os mais comuns são [1, 2]:

- Redução do diâmetro da ventaneira localizada acima da área desgastada do cadinho e uso de válvula de controle de ar quente junto à ventaneira.

- Bloqueio da ventaneira localizada acima da área desgastada do cadinho.

- Redução da produção do Alto-Forno.

- Ativação do centro do cadinho via redução da refrigeração da soleira e aumento da qualidade e granulometria do coque.

- Aumento do coque rate.

- Adequação do PCI.

- Controle do potencial de oxigênio do banho.

- Aumento do comprimento do furo de gusa por meio do aumento da quantidade de massa injetada por tamponamento.

- Carregamento de ilmenita em conjunto da carga metálica do Alto-Forno.

- Co-injeção de dióxido de titânio sintético e carvão via ventaneiras.

- Injeção direta de dióxido de titânio sintético via ventaneira com o uso de um equipamento específico.

O principal objetivo das três últimas técnicas apresentadas anteriormente é o de formar, junto à parede do cadinho, uma camada protetora constituída de carbonitreto de titânio, para prevenir e reconstruir regiões da parede que apresentaram desgaste excessivo.

\subsection{Mecanismo de Formação do Carbonitreto de Titânio na Parede do Cadinho}

O dióxido de titânio introduzido no Alto-Forno por alguns dos três últimos métodos mencionados anteriormente passa, inicialmente, por um processo de diluição do óxido na escória sendo que parte dele, presente na interface ferro gusa / escória, é continuamente reduzido devido ao contato com o coque. O dióxido de titânio também pode ser parcialmente reduzido pelo silício presente no gusa.

O titânio formado é dissolvido no ferro gusa e é transportado até a parede do cadinho que é constituído por blocos de carbono, ocorrendo a formação do carbonitreto de titânio. Com a crescente deposição do carbonitreto de titânio na parede do cadinho, ocorre a formação de uma camada que previne o desgaste excessivo dos blocos de carbono [3].

Todo este mecanismo de formação do carbonitreto de titânio, via adição de fontes de dióxido de titânio no Alto-Forno, está ilustrado na Figura 1. 
Vale ressaltar que, durante a prática de carregamento de fontes de dióxido de titânio no Alto-Forno, é importante que ocorra um ajuste adequado no procedimento operacional a fim de criar uma condição termodinâmica mais favorável possível para incorporação do titânio no ferro gusa, aumentando a eficiência de geração do carbonitreto de titânio junto à parede do cadinho.

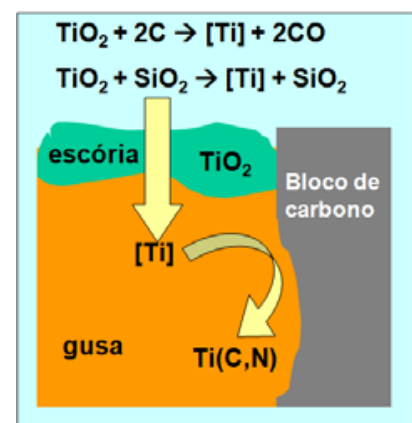

Figura 1. Processo de formação da camada de $T i(C, N)$ na parede do cadinho.

Em função do elevado risco em operar um Alto-Forno com incidência de pontos quentes no cadinho e com o intuito de gerar mais uma opção para enfrentar este problema, neste trabalho será abordado o desenvolvimento de uma nova concepção tecnológica de massa de tamponamento para Altos-Fornos contendo dióxido de titânio sintético.

De uma maneira geral, a região do furo de corrida na parede do cadinho do AltoForno apresenta elevado potencial para desgaste principalmente em função do elevado fluxo de gusa e escória durante o processo de vazamento. Ou seja, é uma região sujeita a apresentar desgaste excessivo sendo de grande importância o uso de uma massa de tamponamento que apresente boa característica de reconstrução / preservação da região desgastada.

\subsection{Componentes das Massas de Tamponamento para Altos-Fornos}

As massas de tamponamento para os furos de corrida de Altos-Fornos é um material refratário monolítico, plástico na temperatura de uso, constituído principalmente de alumina, sílica, carbono, carbeto de silício, nitreto de ferro silício e um ligante. O tipo mais comum de ligante para os produtos utilizados atualmente nos Altos-Fornos do Brasil é o piche proveniente do carvão mineral.

Com a exposição da massa de tamponamento à alta temperatura do furo de corrida do Alto-Forno, diversas reações são desencadeadas no produto. Como exemplo, o nitreto de ferro silício presente na massa de tamponamento sofre, a partir de 1.200 ${ }^{\circ} \mathrm{C}$, reações de decomposição e interações com outros constituintes do produto [4]. Algumas das principais reações são apresentadas na Tabela 1, sendo que, a partir de $1.200^{\circ} \mathrm{C}$, verifica-se a liberação de nitrogênio.

Tabela 1. Reações químicas do nitreto de silício.

\begin{tabular}{lc}
\hline Temperatura & Reações químicas \\
\hline $1.200^{\circ} \mathrm{C}$ & $9 \mathrm{Fe}+\mathrm{Si}_{3} \mathrm{~N}_{4} \rightarrow 3 \mathrm{Fe} \mathrm{S}_{3} \mathrm{Si}+2 \mathrm{~N}_{2}$ \\
\hline $1.300^{\circ} \mathrm{C}$ & $\mathrm{FeSi}+\mathrm{C} \rightarrow \mathrm{Fe}+\mathrm{SiC}$ \\
\hline $1.400^{\circ} \mathrm{C}$ & $3 \mathrm{Fe}+\mathrm{Si}_{3} \mathrm{~N}_{4}+2 \mathrm{C} \rightarrow \mathrm{Fe} \mathrm{Si}_{3}+2 \mathrm{SiC}+2 \mathrm{~N}_{2}$ \\
& $9 \mathrm{Fe}+\mathrm{Si}_{3} \mathrm{~N}_{4}+\mathrm{Al}_{2} \mathrm{O}_{3}+3 \mathrm{C} \rightarrow 2 \mathrm{AIN}+3 \mathrm{Fe} \mathrm{Si}_{3}+3 \mathrm{CO}+\mathrm{N}_{2}$ \\
& $\mathrm{Si}_{3} \mathrm{~N}_{4}+\mathrm{CO} \rightarrow \mathrm{Si}_{2} \mathrm{ON}_{2}+\mathrm{SiC}+\mathrm{N}_{2}$ \\
& $\mathrm{Si}_{3} \mathrm{~N}_{4}+\mathrm{SiO}_{2} \rightarrow 2 \mathrm{Si}_{2} \mathrm{ON}_{2}$ \\
\hline
\end{tabular}


Como essas reações são desenvolvidas na massa em altas temperaturas (após sua aplicação no furo de corrida) e, devido à mesma já conter fontes de carbono, nitrogênio e operar em um ambiente redutor, definiu-se por avaliar a formação do carbonitreto de titânio na massa através da adição do dióxido de titânio sintético em sua formulação. O principal objetivo do desenvolvimento deste novo produto seria ajudar na prevenção da incidência de pontos quentes na parede do cadinho dos Altos-Fornos em regiões próximas aos furos de corrida.

\section{MATERIAIS E MÉTODOS}

\subsection{Caracterização da Fonte de Dióxido de Titânio Sintético}

No desenvolvimento do trabalho, inicialmente foi caracterizada a fonte de dióxido de titânio sintético (T85) para verificar a viabilidade da sua utilização na massa de tamponamento.

A composição química da fonte do dióxido de titânio sintético foi determinada através da técnica de espectometria de fluorescência de raios-X com o equipamento Philips MagiX PRO PW2540.

A determinação das fases cristalinas presentes foram verificadas via difração de raios-X com o equipamento Panalytical, modelo X'Pert Pro. A faixa de estudo foi realizada entre 6 a $90^{\circ} \mathrm{com}$ velocidade de varredura de 0,127 2Theta/s com dispositivo X'Acelerator.

A distribuição do tamanho de partículas foi realizada por meio da técnica de análise de micropartículas com auxílio do equipamento Malvern Mastersizer $S$ utilizando água e pirofosfato de sódio (solução 10\%).

A área superficial foi avaliada por meio da metodologia BET - adsorção por nitrogênio, no equipamento Quantachrome, modelo Monosorb, com uma mistura padrão de hélio e nitrogênio 70/30. Este resultado foi utilizado para avaliar a influência desta matéria-prima na demanda de ligante de cada formulação.

\subsection{Caracterização das Amostras Contendo Dióxido de Titânio Sintético}

Prepararam-se pastilhas contendo dióxido de titânio sintético conforme apresentado na Tabela 2. Esta mistura foi elaborada fazendo uso das principais matérias-primas que compõem as massas de tamponamento. Em seguida prepararam-se pastilhas prensadas no formato de corpos de provas cilíndricos com $35 \times 35 \mathrm{~mm}$, utilizando uma prensa hidráulica com carga de prensagem de $70 \mathrm{MPa}$. Posteriormente essas pastilhas passaram por um processo de queima redutora (caixa de coque) a uma taxa de aquecimento de $100^{\circ} \mathrm{C} /$ hora com patamar de 5 horas nas temperaturas de $1.000^{\circ} \mathrm{C}, 1.200^{\circ} \mathrm{C}, 1.400^{\circ} \mathrm{C}, 1.500^{\circ} \mathrm{C}$ e $1.600^{\circ} \mathrm{C}$.

Tabela 2. Composição da pastilha analisada.

\begin{tabular}{lc}
\hline Matéria-prima & Pastilha 1 (\%) \\
\hline Fontes de carbono & 26 \\
\hline Fe-Si $\mathrm{N}_{4}$ & 53 \\
\hline Dióxido de titânio T85 & 21 \\
\hline Ligante & Resina \\
\hline
\end{tabular}

Com o auxílio da técnica de difração de raios-X, foram determinadas as fases cristalinas presentes nas amostras queimadas nas diferentes temperaturas 
mencionadas. Para isto, estas amostras foram pulverizadas em moinhos de anéis tipo Shaterbox, para análise no difratômetro de raios- $X$ citado anteriormente.

\subsection{Caracterização das Massas de Tamponamento Contendo Dióxido de Titânio}

Conforme apresentado na Tabela 3, algumas amostras de formulações de massas de tamponamento contendo diferentes teores da fonte de dióxido de titânio sintético foram analisadas no laboratório. As formulações testadas foram comparadas com a formulação padrão A1 que não continha o dióxido de titânio.

Tabela 3. Composição das massas de tamponamento analisadas

\begin{tabular}{|c|c|c|c|}
\hline Matéria-prima & A1 (\%) & A2 (\%) & A3 (\%) \\
\hline Alumina & 25 & $25-x$ & $25-2 x$ \\
\hline Carbono & 20 & 20 & 20 \\
\hline $\mathrm{Fe}-\mathrm{Si}_{3} \mathrm{~N}_{4}$ & 20 & 20 & 20 \\
\hline $\mathrm{SiO}_{2}+\mathrm{SiC}$ & 35 & 35 & 35 \\
\hline Dióxido de titânio T85 & - & $\mathrm{X}$ & $2 x$ \\
\hline
\end{tabular}

Para realização dos ensaios, os corpos de provas foram conformados em barras seguindo as dimensões e pressões de compactação citados na Tabela 4. Todos esses corpos de prova passaram por um tratamento térmico na temperatura de $1.200^{\circ} \mathrm{C}$, com 5 horas de patamar, a uma taxa de aquecimento de $100^{\circ} \mathrm{C} /$ hora e em atmosfera redutora (caixa de coque).

$\mathrm{O}$ ensaio de corrosão no forno de indução foi realizado a $1.650{ }^{\circ} \mathrm{C}$ durante 90 minutos utilizando gusa e 3 adições de escória de Alto-Forno a cada 30 minutos. Antes do ensaio, foram registradas as dimensões originais das amostras e, após o ensaio, foi medido o percentual de desgaste sofrido nestas amostras, tanto na região de contato com a escória como na região de contato com o gusa.

Tabela 4. Dimensões e pressões de compactação para conformação dos corpos de provas.

\begin{tabular}{cccc}
\hline $\begin{array}{c}\text { Corpos de provas } \\
(\mathbf{m m})\end{array}$ & $\begin{array}{c}\text { Pressão de } \\
\text { compactação }(\mathrm{MPa})\end{array}$ & Ensaios & $\begin{array}{c}\text { Norma } / \\
\text { procedimento }\end{array}$ \\
\hline $160 \times 40 \times 40$ & 8,5 & DA, PA e RCTA & ABNT NBR 11220 \\
\hline $160 \times 85 \times 55$ & 47 & Corrosão no FI & $\begin{array}{c}\text { Magnesita MPDD-I- } \\
099\end{array}$ \\
\hline
\end{tabular}

Uma característica importante avaliada nas misturas é o teor de ligante demandado para uma mesma faixa de índice de extrusão, parâmetro este correspondente a plasticidade do material. No geral, objetiva-se sempre trabalhar com o menor teor possível deste ligante, para uma determinada faixa de plasticidade, a fim de se obter as melhores propriedades do material.

O índice de extrusão objetivado para as composições testadas foi entre 15 e $17 \mathrm{MPa}$ e o ensaio executado segundo os procedimentos descritos na norma ABNT NBR 9881.

Por fim, após a etapa de desenvolvimento laboratorial do produto, foi testado no Alto-Forno 3 da Usiminas-Ipatinga uma nova concepção tecnológica de massa de tamponamento contendo dióxido de titânio sintético. 


\section{RESULTADOS E DISCUSSÃO}

\subsection{Resultados da Caracterização da Fonte de Dióxido de Titânio}

$\mathrm{Na}$ Tabela 5, encontram-se os resultados obtidos da caracterização da fonte de dióxido de titânio sintético analisada.

Tabela 5. Resultados da caracterização da fonte de dióxido de titânio sintético.

\begin{tabular}{|c|c|}
\hline Análise química & Teor (\%) \\
\hline $\mathrm{TiO}_{2}$ & 82,7 \\
\hline $\mathrm{SiO}_{2}$ & 7,36 \\
\hline $\mathrm{Al}_{2} \mathrm{O}_{3}$ & 2,18 \\
\hline $\mathrm{Fe}_{2} \mathrm{O}_{3}$ & 2,06 \\
\hline $\mathrm{Na}_{2} \mathrm{O}+\mathrm{K}_{2} \mathrm{O}+\mathrm{P}_{2} \mathrm{O}_{5}$ & 1,07 \\
\hline \multicolumn{2}{|l|}{ Difração de raios-X } \\
\hline \multicolumn{2}{|l|}{ Anatásio, rutilo e $\mathrm{Fe}_{2} \mathrm{TiO}_{5}$} \\
\hline \multicolumn{2}{|c|}{ Distribuição do tamanho de partícula - Malvern $(\mu \mathrm{m})$} \\
\hline $\mathrm{D}(0,10)$ & 0,28 \\
\hline $\mathrm{D}(0,25)$ & 0,48 \\
\hline $\mathrm{D}(0,50)$ & 0,95 \\
\hline $\mathrm{D}(0,75)$ & 5,70 \\
\hline $\mathrm{D}(0,90)$ & 26,78 \\
\hline $\mathrm{D}(0,98)$ & 57,44 \\
\hline Área superficial - BET $\left(\mathrm{m}^{2} / \mathrm{g}\right)$ & 5,81 \\
\hline
\end{tabular}

O dióxido de titânio sintético analisado apresenta elevado nível de pureza e um baixo teor de álcalis sendo compatível com o sistema da massa de tamponamento. Além disso, sua distribuição do tamanho de partículas e área superficial pode ser considerada similar às matérias-primas que compõem a matriz da massa.

\subsection{Resultado da Caracterização das Pastilhas Contendo Dióxido de Titânio Sintético}

$\mathrm{Na}$ Tabela 6, encontram-se os resultados das principais fases presentes através da análise de difração de raios- $X$ nas pastilhas preparadas com o dióxido de titânio sintético e que foram previamente queimadas em diferentes temperaturas.

Tabela 6. Resultado da análise de raios-X nas pastilhas com dióxido de titânio sintético.

\begin{tabular}{cc}
\hline Temperatura de queima & Fases cristalinas presentes \\
\hline $1.000^{\circ} \mathrm{C}$ & Nitreto de silício, rutilo, $\mathrm{Fe}_{3} \mathrm{Si}$ e traços de anatásio \\
\hline $1.200^{\circ} \mathrm{C}$ & $\begin{array}{r}\text { Nitreto de silício, cristobalita, nitreto de titânio e traços de } \\
\text { rutilo e } \mathrm{Fe}_{2} \mathrm{Ti}_{3} \mathrm{O}_{9}\end{array}$ \\
\hline $1.400^{\circ} \mathrm{C}$ & $\begin{array}{c}\text { Nitreto de silício, cristobalita, nitreto de titânio e traços de } \\
\text { rutilo, } \mathrm{Fe} \mathrm{Se}_{3} \mathrm{Si} \text { e grafita }\end{array}$ \\
\hline $1.500^{\circ} \mathrm{C}$ & $\begin{array}{c}\text { Presença de traços da fase carbonitreto de titânio } \\
\left(\mathrm{TiC}_{0,3} \mathrm{~N}_{0,7}\right)\end{array}$ \\
\hline $1.600^{\circ} \mathrm{C}$ & $\begin{array}{c}\text { Redução da cristobalita e aumento da incidência da fase } \\
\text { carbonitreto de titânio. Presença das fases sinoita } \\
\left(\mathrm{Si}_{2} \mathrm{ON} \mathrm{N}_{2}\right), \text { rutilo, carbeto de silício, grafita e FeO. Não } \\
\text { verificou-se presença da fase nitreto de silício }\end{array}$ \\
\hline
\end{tabular}




\subsection{Resultado da Caracterização da Massa de Tamponamento Contendo Dióxido de Titânio Sintético}

Conforme apresentado na Tabela 7, a introdução da fonte de dióxido de titânio na massa de tamponamento proporcionou pequeno aumento no teor de piche considerando uma mesma faixa de plasticidade do produto. Isto provavelmente ocorreu devido à característica granulométrica (teor de partículas finas) e área superficial do dióxido de titânio que aumentou, de uma maneira geral, o teor de material impalpável da matriz da massa de tamponamento.

Tabela 7. Resultado do teor de piche e índice de extrusão entre as formulações de massa de tamponamento analisadas.

\begin{tabular}{lccc}
\hline & A1 (\%) & A2 (\%) & A3 (\%) \\
\hline \% de piche & 17,74 & 18,13 & 18,65 \\
\hline Índice de extrusão (MPa) & 16,29 & 16,86 & 15,45 \\
\hline
\end{tabular}

Na Figura 2 encontram-se os resultados obtidos para a DA $\left(\mathrm{g} / \mathrm{cm}^{3}\right)$, PA (\%) e RCTA (MPa) dos produtos analisados. De uma maneira geral, os resultados obtidos para estas propriedades encontram-se muito similares entre a formulação padrão e as formulações contendo o dióxido de titânio sintético, principalmente a formulação A2. Quanto a formulação $A 3$, ela apresentou maior PA e menor RCTA em relação às demais testadas.

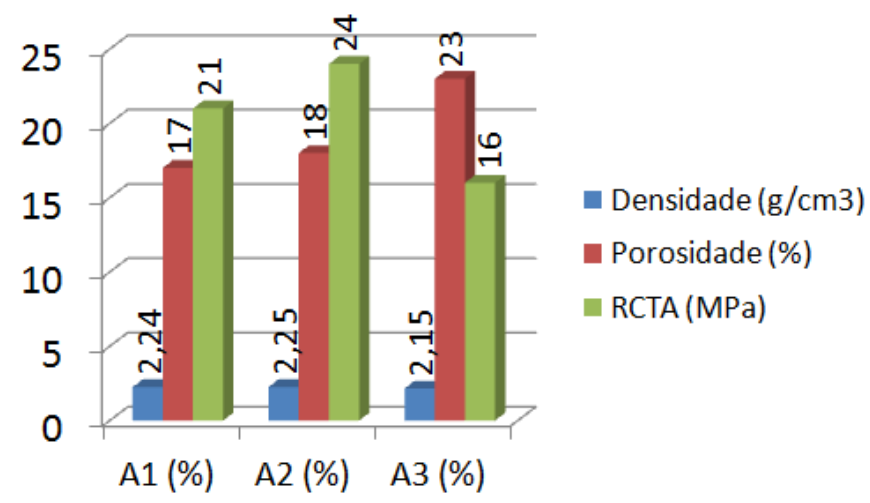

Figura 2. Resultado das propriedades das massas de tamponamento analisadas após tratamento térmico das amostras a $1.200^{\circ} \mathrm{C}$.

$\mathrm{Na}$ Figura 3, seguem os resultados obtidos no teste de corrosão no forno de indução (FI) entre as amostras de massa de tamponamento. Conforme observado, as amostras contendo dióxido de titânio sintético apresentaram menor desgaste na região de contato com o gusa (linha de metal). Com relação ao desgaste na região de contato com a escória, as formulações apresentaram níveis de desgaste considerados similares, com exceção da formulação $A 3$, que apresentou um desgaste mais acentuado nesta região.

Os resultados apresentados na caracterização de laboratório para a formulação A3 foram inferiores em relação às demais formulações analisadas. Isto provavelmente ocorreu em função da maior demanda de piche que esta formulação apresentou levando a um aumento de sua PA com queda da DA, conforme evidenciado nos testes realizados após tratamento térmico da amostra a $1.200^{\circ} \mathrm{C}$. Além disso, a queda nas propriedades físicas desta amostra também comprometeu o seu resultado com relação à resistência ao ataque de gusa e escória de Alto-Forno. 
Desta forma, optou-se então por avaliar, em um teste de campo, o uso de uma massa de tamponamento com uma formulação similar à formulação A2. Estes testes foram conduzidos no Alto-Forno 3 da Usiminas-Ipatinga.

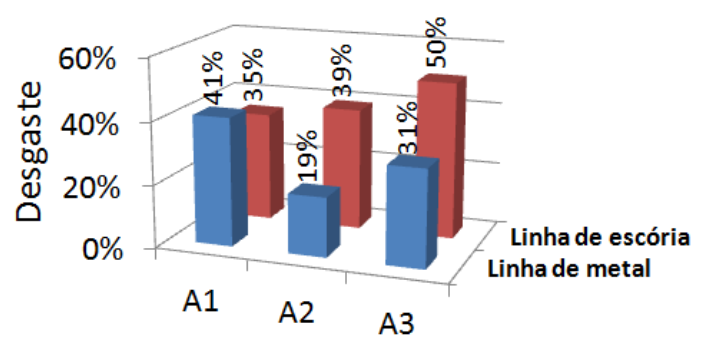

Figura 3. Resultado do teste de corrosão no forno de indução.

\subsection{Resultados do Desempenho do Uso da Massa de Tamponamento Contendo Dióxido de Titânio Sintético no Alto-Forno 3 na Usiminas-Ipatinga}

A Usina de Ipatinga possui 3 Altos-Fornos, sendo que os Altos-Fornos 1 e 2 possuem volume interno de $885 \mathrm{~m}^{3}$ e, o Alto-Forno 3, que responde por aproximadamente $70 \%$ da produção de gusa, possui volume interno de $3.163 \mathrm{~m}^{3}$. A Tabela 8 descreve as principais características do Alto-Forno 3.

Tabela 8. Principais características do Alto-Forno 3 da Usiminas-Ipatinga

\begin{tabular}{lc}
\hline Item & Valor \\
\hline Diâmetro do cadinho $(\mathrm{m})$ & 12,2 \\
\hline Capacidade de produção (t/dia) & 8.200 \\
\hline Número de ventaneiras & 30 \\
\hline Número de furos de gusa & 3 \\
\hline Temperatura de sopro máxima $\left({ }^{\circ} \mathrm{C}\right)$ & 1.200 \\
\hline Refrigeração rampa, ventre e cuba & stave-cooler \\
\hline Refrigeração do cadinho & stave-cooler \\
\hline Início da campanha atual & $29 / 10 / 1999$ \\
\hline
\end{tabular}

Com a retomada da produtividade a partir de março de 2009, as temperaturas dos blocos de carbono da parede do cadinho, principalmente no GL+6685 mm (ground level), começaram a elevar-se. Primeiramente, próximo ao furo de gusa 2 (FG2), ângulo $174^{\circ} \mathrm{e}$, posteriormente, na região do furo de gusa 1 (FG1), ângulo $7^{\circ}$.

Desta forma, além de continuar com os procedimentos operacionais usuais no AltoForno 3 para controle e estabilização dos pontos quentes, optou-se também pelo uso da nova concepção de massa de tamponamento contendo dióxido de titânio sintético, uma vez que o ponto quente estava localizado bem próximo ao FG1.

Os testes com a massa de tamponamento contendo o dióxido de titânio sintético foram realizados em 3 etapas, sendo consumidas aproximadamente 200 toneladas de material. Para avaliação do desempenho desse produto (Tabela 9 e Figuras 4 a 6 ), optou-se por comparar as variáveis de controle do seu desempenho com o do produto de linha utilizado usualmente no forno. Além disso, a temperatura registrada no termopar na região do FG1 foi constantemente monitorada durante os testes.

Analisando os resultados obtidos e em função do baixo valor da presença de trincas, conclui-se que a massa de tamponamento contendo o dióxido de titânio sintético não apresentou excessiva sinterização dificultando a operação de perfuração do furo de corrida. Além disso, verificou-se que o tempo de corrida durante o uso desse produto foi similar ao produto de linha mantendo o nível de produção do Alto-Forno. Exceção 
foi o primeiro teste no qual o tempo de corrida com o produto de teste foi inferior. Esta queda não foi atribuída ao uso do produto experimental, uma vez que nos testes posteriores este fato não se repetiu e a quantidade de material testada no primeiro teste foi muito inferior em relação aos demais.

Com relação à preservação da região do furo de corrida com o uso do novo produto, verificou-se que o mesmo apresenta melhor recuperação e preservação do comprimento de furo em relação ao produto de linha. Este fato contribuiu positivamente com a operação do Alto-Forno 3 , mesmo com uma elevada incidência de retorno de massa durante o período de teste, retorno este que compromete a recuperação e estabilização do comprimento do furo de corrida.

Tabela 9. Parâmetros de controle do desempenho da massa de tamponamento.

\begin{tabular}{|c|c|c|c|c|c|c|}
\hline \multirow[t]{2}{*}{ Item } & \multicolumn{2}{|c|}{$1^{\circ}$ teste: 15 toneladas } & \multicolumn{2}{|c|}{$2^{\circ}$ teste: 35 toneladas } & \multicolumn{2}{|c|}{$3^{\circ}$ teste: 110 toneladas } \\
\hline & $\begin{array}{c}\text { Produto de } \\
\text { linha }\end{array}$ & $\begin{array}{l}\text { Produto de } \\
\text { teste }\end{array}$ & $\begin{array}{l}\text { Produto de } \\
\text { linha }\end{array}$ & $\begin{array}{l}\text { Produto de } \\
\text { teste }\end{array}$ & $\begin{array}{c}\text { Produto de } \\
\text { linha }\end{array}$ & $\begin{array}{c}\text { Produto de } \\
\text { teste }\end{array}$ \\
\hline $\begin{array}{l}\text { Tempo de corrida } \\
\text { (min) }\end{array}$ & 177 & 154 & 166 & 173 & 146 & 150 \\
\hline Gusa/corrida (t) & - & - & - & - & 618 & 688 \\
\hline $\begin{array}{l}\text { Comprimento FG } \\
(\mathrm{cm})\end{array}$ & 320 & 323 & 317 & 339 & 326 & 345 \\
\hline $\begin{array}{l}\text { Retorno de massa } \\
(\%)\end{array}$ & 21 & 40 & 10 & 14 & 14 & 8 \\
\hline $\begin{array}{l}\text { Consumo específico } \\
\text { (kg/t de gusa) }\end{array}$ & 0,41 & 0,41 & 0,62 & 0,46 & 0,55 & 0,52 \\
\hline Trincas (\%) & - & - & 0 & 0 & 2,8 & 2,0 \\
\hline
\end{tabular}

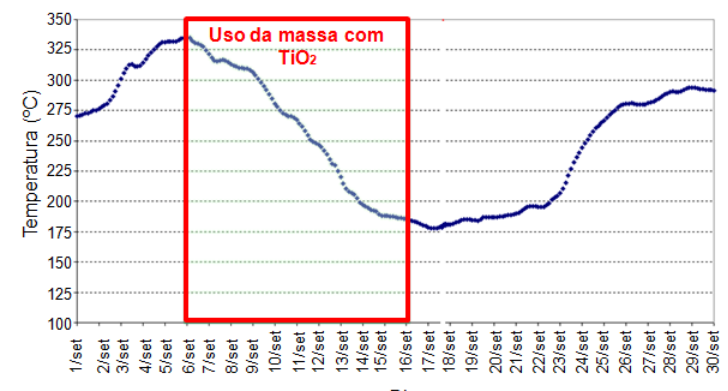

Dia

Figura 4. Temperatura do termopar (TI63101 - ângulo 14,5º próximo ao FG1 durante $1^{\circ}$ teste.

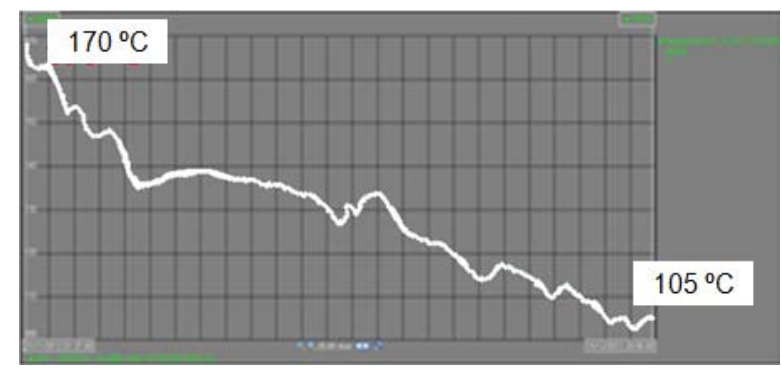

Figura 5. Temperatura do termopar (TI63101 - ângulo 14,5ํ) próximo ao FG1 durante $2^{\circ}$ teste.

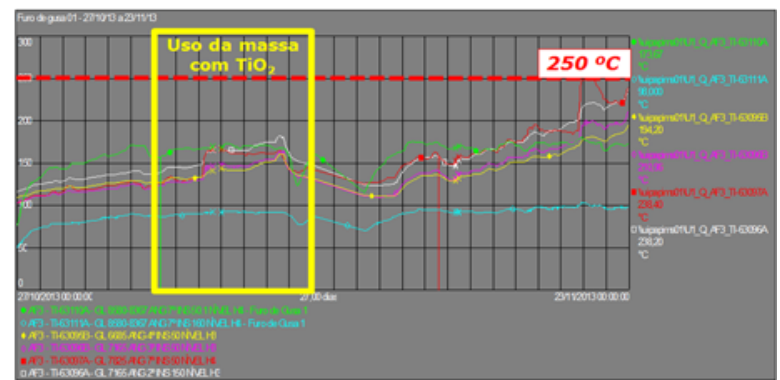

Figura 6. Temperatura dos termopares próximos ao FG1 durante $3^{\circ}$ teste. 
Por fim, das análises das temperaturas dos termopares durante testes com o novo produto, verificou-se no $1^{\circ}$ e $2^{\circ}$ testes redução dessa temperatura durante uso da nova massa de tamponamento. Entretanto, no $1^{\circ}$ teste, não foi possível associar este efeito exclusivamente à massa experimental, pois a temperatura da parede do cadinho chegou a valores muito elevados. Desta forma, foram tomadas diversas medidas operacionais, além do uso da nova massa, para tentar controlar e reduzir esta temperatura.

Entretanto, durante $\circ 2^{\circ}$ teste, como a temperatura do furo de corrida não estava em uma condição considerada crítica, ou seja, não estava sendo necessária a prática de nenhuma alteração da condição operacional do Alto-Forno 3 para controle da temperatura da parede do cadinho, a única variável que estava naquele momento atuando para reduzir a temperatura era o uso da nova massa de tamponamento. Entretanto, esta redução de temperatura não ocorreu da mesma forma no $3^{\circ}$ teste, sendo que, durante este período, verificou-se uma estabilização da temperatura de todos os termopares próximos ao furo de corrida 1, mesmo com o uso do produto convencional do Alto-Forno 3.

\section{CONCLUSÃO}

Uma nova concepção de massa de tamponamento contendo dióxido de titânio sintético para controle e estabilização de pontos quentes em cadinhos de AltosFornos foi desenvolvida e sua utilização foi também avaliada em campo durante 3 etapas de testes no Alto-Forno 3 da Usiminas-Ipatinga, totalizando um consumo aproximado de 200 toneladas.

No laboratório, constatou-se, a partir de queimas a $1.500^{\circ} \mathrm{C}$ em atmosfera redutora, a formação da fase carbonitreto de titânio em função da reação do dióxido de titânio sintético com outros aditivos que fazem parte da constituição do produto.

Nos testes em campo, verificou-se que o produto contribuiu com relação à recuperação e estabilização do comprimento do furo de corrida, sendo o seu uso uma nova alternativa para auxiliar no controle e estabilização de pontos quentes em regiões da parede do cadinho próximo aos furos de corrida.

\section{REFERÊNCIAS}

1 Manso GAC, Santos GS, Oliveira MAG, Fernandes MV, Amirzadeh-AsI D, Funders D. Hearth protection of Blast Furnace \# 3 of Usiminas by injection titanium dioxide products. Ironmaking Conference. 2011; 8: 455-464.

2 Korthas B, Hunger J, Pschebezin V, Adam J, Harp G, Kallio S, Hurme R, Wikstrom J, Hahlin P, Wiedner S, Di Sante L, Gelli I. Hearth protection in blast furnace operation by injection of $\mathrm{TiO}_{2}$ materials. European Comission - Technical Steel Researsh - Ore agglomeration and Ironmaking. 2007.

3 Hartig W, Amirzadeh-AsI D, Funders D. Use of synthetic titanium products for protection of the hearth of Rogesa blast furnace. Ironmaking and Raw Materials Seminar. 2007; 37.

4 Ribeiro AS. Análise Sistêmica das Massas de Tamponamento para Altos-Fornos. 2010 [acesso em 01 março 2015]. Disponível em:

http://www.bdtd.ufscar.br/htdocs/tedeSimplificado//tde_busca/arquivo.php?codArquivo= 3536. 